\title{
Flow Effects due to Valve and Piston Motion in an Internal Combustion Engine Exhaust Port
}

\author{
Bernhard Semlitsch $^{\mathrm{a}, *}$, Yue Wang ${ }^{\mathrm{b}}$, Mihai Mihăescu ${ }^{\mathrm{a}}$ \\ ${ }^{a}$ Linné FLOW Center - Competence Center for Gas Exchange (CCGEx), Department of Mechanics, Royal Institute of Technology (KTH), Osquars \\ Backe 18, Stockholm, 10044, Sweden \\ ${ }^{b}$ National Key Laboratory of Aerodynamic Design and Research, Northwestern Polytechnical University, Youyi West Road, No. 127, Xi'an, \\ Shaanxi, 710072 ,China
}

\begin{abstract}
Performance optimization regarding e.g. exhaust valve strategies in an internal combustion engine is often performed based on one-dimensional simulation investigation. Commonly, a discharge coefficient is used to describe the flow behavior in complex geometries, such as the exhaust port. This discharge coefficient for an exhaust port is obtained by laboratory experiments at fixed valve lifts, room temperatures, and low total pressure drops. The present study investigates the consequences of the valve and piston motion onto the energy losses and the discharge coefficient. Therefore, Large Eddy Simulations are performed in a realistic internal combustion geometry using three different modeling strategies, i.e. fixed valve lift and fixed piston, moving piston and fixed valve lift, and moving piston and moving valve, to estimate the energy losses. The differences in the flow field development with the different modeling approaches is delineated and the dynamic effects onto the primary quantities, e.g. discharge coefficient, are quantified. Considering the motion of piston and valves leads to negative total pressure losses during the exhaust cycle, which cannot be observed at fixed valve lifts. Additionally, the induced flow structures develop differently when valve motion is taken into consideration, which leads to a significant disparity of mass flow rates evolving through the two individual valve ports. However, accounting for piston motion and limited valve motion, leads to a minor discharge coefficient alteration of about one to two percent.
\end{abstract}

Keywords: Internal combustion engines, Fuel economy, Turbocharged engines, Exhaust gas energy, Exhaust port, Large Eddy Simulation

\begin{tabular}{ll}
\multicolumn{2}{l}{ Nomenclature } \\
\multicolumn{2}{l}{ Latin symbols } \\
$A_{R}$ & reference area $\left(\mathrm{m}^{2}\right)$ \\
$C_{D}$ & discharge coefficient $(-)$ \\
$C_{F}$ & flow coefficient $(-)$ \\
$d_{e}$ & exhaust pipe diameter $(\mathrm{m})$ \\
$D_{v}$ & valve head diameter $(\mathrm{m})$ \\
$e$ & specific internal energy $(\mathrm{J} / \mathrm{kg})$ \\
$\dot{m}_{\text {real }}$ & actual mass flow rate $(\mathrm{kg} / \mathrm{s})$ \\
$L_{v}$ & valve lift $(\mathrm{m})$ \\
$p$ & pressure $(\mathrm{Pa})$ \\
$q$ & heat flux $\left(\mathrm{W} / \mathrm{m}^{2}\right)$ \\
$R$ & specific gas constant $(\mathrm{J} /(\mathrm{kgK}))$ \\
$S$ & strain rate tensor $(1 / \mathrm{s})$ \\
$t$ & time $(\mathrm{s})$
\end{tabular}

${ }^{*}$ Tel. +4687907157 / Fax: +4687969850

Email address: bernhard@mech.kth.se (Bernhard Semlitsch)

$\begin{array}{ll}T & \text { temperature }(\mathrm{K}) \\ u & \text { velocity }(\mathrm{m} / \mathrm{s}) \\ x & \text { spatial coordinate }(\mathrm{m}) \\ \text { Greek symbols } \\ \delta & \text { Kronecker-delta function }(-) \\ \rho & \text { density }\left(\mathrm{kg} / \mathrm{m}^{3}\right) \\ \mu & \text { dynamic viscosity }(\mathrm{Pa} \cdot \mathrm{s}) \\ \gamma & \text { ratio of specific heats }(-) \\ \sigma & \text { viscous stress tensor }(\mathrm{Pa})\end{array}$

Abbreviations

$\begin{array}{ll}\text { ALE } & \text { Arbitrary Largranian-Eulerian } \\ \text { CAD } & \text { Crank Angle Degrees (deg) } \\ \text { LES } & \text { Large Eddy Simulation } \\ \text { PIV } & \text { Particle Image Velocimetry } \\ \text { RANS } & \text { Reynolds Averaged Navier-Stokes } \\ \text { Subscripts } & \\ 0 & \text { stagnation or total state } \\ \text { s } & \text { static state }\end{array}$

December 14, 2014 


\section{Introduction}

The exhaust gases of an internal combustion engine are hot and therefore rich in available energy [1]. Additionally, the pressure remaining in the cylinder after the working cycle is higher than the pressure downstream of the exhaust. This potential should be expanded as much as possible, since the remaining sources of energy in the residual gas after combustion can represent up to $40 \%$ of the total amount of energy, which has been made available by the fuel combustion process. Since this proportion constitutes a large amount of the total energy, it is important to extract as much as possible energy before releasing the exhaust gases into the ambient. This can be accomplished by using a turbocharger to increase the specific engine efficiency. The exhaust port represents the interface between the internal combustion engine cylinder and the exhaust manifold followed by the turbocharger. Hence, the available energy after combustion shall be transmitted from the cylinder to the turbocharger inducing minimal losses. Nonetheless, the efficiency of the turbocharger turbine is sensitive to the flow conditions at the inlet. Thus, the exhaust port should not only be designed with the intention to minimize losses, moreover the effectiveness of the generated flow structures transmitted to the turbocharger turbine should be considered. The energy content associated with these structures and their behavior may influence the engine efficiency potentially higher than the flow losses in the port itself.

Considering the heat transfer problem is of interest to design the exhaust port material and to predict accurately the efficiency of the turbocharger, catalytic converters, thermal reactors, and after treatment devices. Caton and Heywood [2] investigated the heat transfer in an exhaust port geometry of a spark ignition engine experimentally and an analytical model predicting the heat transfer was developed. It was found that the heat transfer cannot be modeled accurately by considering only one single dominant mode. Further, Caton and Heywood state that the flow regimes need to be considered for precise predictions. The flow in the exhaust port is dominated by the large scale turbulent flow structures and not by the wall shear generated turbulence. These large, energy containing structures and their behavior influence the heat transfer. Torregrosa et al. [3] found experimentally that the transient heat transfer is primarily affected by the gas temperatures in the cylinder rather than the cylinder wall temperatures. There- fore, the assessment of the flow structures evolving in the exhaust port is important.

The design and optimization process of an internal combustion engine is commonly performed using onedimensional simulations. The entire engine with all relevant components is considered in one model. Since a number of parts need to be incorporated into the complete model, simplifications are required to provide a solution in reasonable time. With such simulations, optimization of parameters, as e.g. the effect of valve timing [4] or injection timing [5], can be effectively studied [6]. The efficiency of the exhaust port from fluid dynamics perspective, is assessed by estimations of flow and discharge coefficients. Such a flow or discharge coefficient can be obtained by a so-called flow bench measurement. The flow bench experiment consists of measuring the resultant mass flow rate through the actual geometry for fixed pressure drops at fixed valve lifts and laboratory conditions [7, 8, 9].

The discharge coefficient $C_{D}$ is commonly used to account for flow losses caused within the real geometry, compared to the ideal achieved value. Therefore, the discharge coefficient $C_{D}$ is defined as the ratio of the actual measured mass flow rate $\dot{m}_{\text {real }}$ to the ideal (theoretical) mass flow rate resulting from the isentropic relations,

$$
C_{D}=\dot{m}_{\text {real }} \frac{\sqrt{R T_{0}}}{A_{R} p_{0}}\left(\frac{p_{0}}{p_{s}}\right)^{\frac{1}{\gamma}} \cdot\left(\frac{2 \gamma}{\gamma-1}\left[1-\left\{\frac{p_{s}}{p_{0}}\right\}^{\frac{\gamma-1}{\gamma}}\right]\right)^{-\frac{1}{2}},
$$

where $R$ is the specific gas constant, $T_{0}$ is the in-cylinder total temperature, $p_{0}$ is the in-cylinder total pressure, $p_{s}$ is the static pressure at the flow restriction, $A_{R}$ is the reference area, and $\gamma$ is the ratio of specific heats. The reference area $A_{R}$ is commonly calculated as the valve curtain area $\pi D_{v} L_{v}$, where $D_{v}$ is the valve head diameter and $L_{v}$ is the valve lift. In the specific literature, the flow coefficient $C_{F}$ refers to the outer valve head area $D_{v}^{2} \pi / 4$ as reference area $A_{R}$. Both coefficients are used in one-dimensional internal combustion engine analysis, where Algieri [10] illustrates the behavior of the two coefficients as a function of the crank angle based on experimental data.

For a physically appropriate approximation of the flow induced losses by Eq. 11 the smallest effective cross-sectional area should be considered as reference area. Figure 1 shows a schematic of different crosssectional area choices for the reference area. An accurate estimation of the smallest effective cross-sectional 


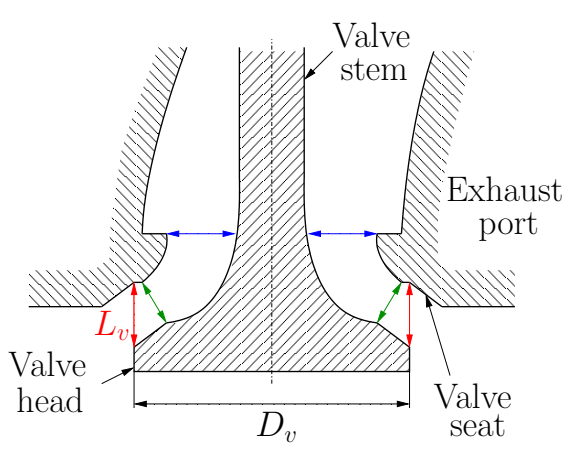

Figure 1: The different reference area $A_{R}$ formulations are sketched. The valve curtain area is indicated by the red line, the blue line shows the minimal effective cross-sectional area for large valve lifts, and the green lines reveal the minimal effective cross-sectional area for the sketched valve lift.

area might be difficult to asses, since the smallest crosssectional area for the flow might not be the smallest geometrical cross-section. Nevertheless, for small valve lifts, this approximation might be applicable when used consistently. Hence, the same formula is applied for all compared cases. At large valve lifts, the valve curtain area might not be the smallest effective cross-sectional area any more. The smallest effective cross-sectional area for large valve lifts is the valve port entrance crosssection subtracted by the valve stem cross-section (indicated by the blue line in Fig. 1). Therefore, the smallest effective cross-section is constant independent on the valve lift at large valve lifts, which is met by reference area formulation contained in the flow coefficient.

Many research groups investigated the flow field in the intake tract of an internal combustion engine, since the generated flow structures effect the fuel mixing in the cylinder and therefore the performance of the engine. A fewer number of investigations treat the flow in the exhaust port. The experimental flow visualization of the exhaust port flow is challenging due to the complex, confined geometry. Nevertheless, the flow field has been exposed by several researchers, as e.g. [11]. Tanaka [12] investigated the flow in a two-dimensional exhaust geometry. Several chamfer configurations at the valve edges have been investigated. Different exhaust port flow regimes have been reported to occur accordingly to the valve lift $L_{v}$ with respect to the valve head diameter $D_{v}$. For small valve lifts, a convergent, conical jet forms, which is sketched in Fig. 2 (a). A jet coaxial with the valve stem establishes for large valve lifts, as illustrated in Fig. 2](b). Annand and Row [13] suggest a transition between the two flow regimes at a valve lift to valve diameter ratio $L_{v} / D_{v}$ of 0.2 . This ratio was proposed based on measurements, which indicated

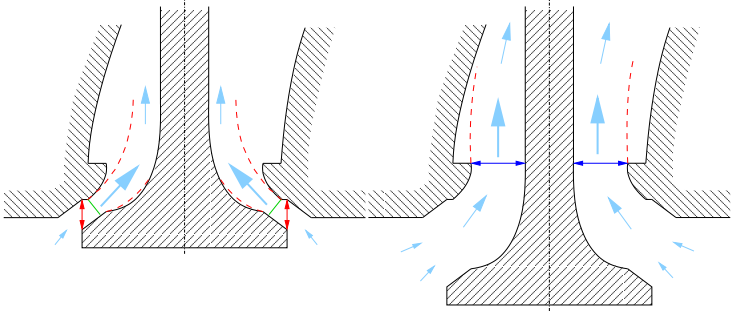

$\begin{array}{ll}\text { (a) low valve lifts } & \text { (b) large valve lifts }\end{array}$

Figure 2: Illustration of the exhaust port flow regimes, where (a) shows the contracting, conical jet developing for low valve lifts and (b) demonstrates the coaxial jet forming for high valve lifts. The red dashed lines represent the jet shear layer.

a decrease in the discharge coefficient at higher valve lifts than this ratio. Nonetheless, a comprehensive assessment of the flow field in the exhaust port remains challenging. Therefore, several numerical approaches have been used to simulate the gas outtake process of the internal combustion engine. The investigation of the unsteady, three-dimensional flow field requires a simulation approach, which resolves these characteristics. Commonly unsteady Reynolds-Averaged Navier-Stokes (RANS) simulations [14] and LES simulations [15] are utilized to investigate the dynamic response of the high turbulent, three-dimensional flow in a complex geometry. The unsteady RANS approach is computationally less demanding, since the underlying turbulence model allows using a coarse mesh grid compared to the grid required for LES simulations. Nevertheless, the turbulence closure model used in the unsteady RANS simulations is based on simplifying assumptions and tuning of the closure coefficients may be required. Hence, this approach needs to be carefully validated before used [15]. The computationally more expensive LES approach requires fewer assumptions and is therefore more reliable.

Wang et al. [15] investigated numerically the sources of the total pressure losses in an exhaust port geometry. For small fixed valve lifts at room temperatures, the total pressure losses over the exhaust port were divided into sections and the major cause of the loss was identified by comparison to empirical formulas. The alternation of the flow coefficient obtained with five different exhaust port geometries under constant and pulsating inflow boundary conditions have been investigated by Bohac and Landfahrer [9]. The experimental setup was a flow bench measurement at fixed valve lifts and room temperatures, where a variation of $6 \%$ increase and $7 \%$ decrease of the flow coefficient has been observed. When averaged over different valve lifts, an increase of the flow coefficient of $0.5-2.5 \%$ was mea- 
sured. Therefore, Bohac and Landfahrer concluded that this percentage is small compared to the total engine performance and steady flow bench measurements are a valid assumption to obtain the flow coefficient used for the engine optimization. Semlitsch et al. [16] investigated the flow dynamics in an exhaust port with and without flow pulsation. The same trend for the discharge coefficients was observed as reported by Bohac and Landfahrer [9]. Semlitsch et al. [16] showed that the flow structures evolve significantly different under engine-like pulsatile conditions. Nevertheless, the investigations listed in this paragraph consider room temperatures and fixed valve lifts in order to mimic flow bench experiments. Hence, the effect of the valve dynamics and the hot exhaust gas temperatures occurring in real internal combustion engines have not been considered.

In the present investigation, the effect of piston and valve motion on the flow field and the discharge coefficient predictions is analyzed numerically for hot enginelike conditions. Therefore, three simulation strategies are compared, i.e. fixed valve and fixed piston, fixed valve and moving piston, and moving valve and moving piston. The flow field resulting for each of the different approaches is briefly described and analyzed. The flow variables governing the performance of the exhaust port design are sampled over the exhaust cycle and compared. Thereby, the investigation elucidates the consequences of applying a fixed valve lift, "cold" laboratory conditions, and a constant inflow boundary condition for evaluating the discharge coefficient as compared to a real engine case scenario. One has to note that fixed valve lifts and cold flow conditions are characteristic to the flow bench experiments typically carried out in industry.

\section{Case Description}

The geometry used for the simulations is the exhaust port of the SCANIA D12, a heavy-duty four stroke Diesel engine. The specifications of the internal combustion engine are listed in Tab. 1. For this study only the exhaust tract is relevant. Therefore, the intake ports have been removed. The geometry used for the numerical simulations is show in Fig. 3 and embodies six main parts, i.e. the cylinder pod, the piston, the valves, the valve port, and the exit pipe. A fictitious straight exit pipe is attached at $y=0$ prolonging the port geometry by ten exhaust port diameters $\left(d_{e}=42 \mathrm{~mm}\right)$ to smoothly propagate the flow structures out of the computational domain. The valve ports are named $L$ valve port and $R$
Table 1: Specifications of the internal combustion engine.

\begin{tabular}{lrl}
\hline \hline parameter & value & unit \\
\hline Displacement & 11.7 & $\mathrm{dm}^{3}$ \\
Bore & 127 & $\mathrm{~mm}$ \\
Stroke & 154 & $\mathrm{~mm}$ \\
Conn. rod length & 255 & $\mathrm{~mm}$ \\
Compression ratio & 18 & - \\
Exhaust valve opening & 136 & $\mathrm{CAD}$ \\
Exhaust valve closing & 359 & $\mathrm{CAD}$ \\
Engine speed & 1200 & $\mathrm{rpm}$ \\
\hline \hline
\end{tabular}

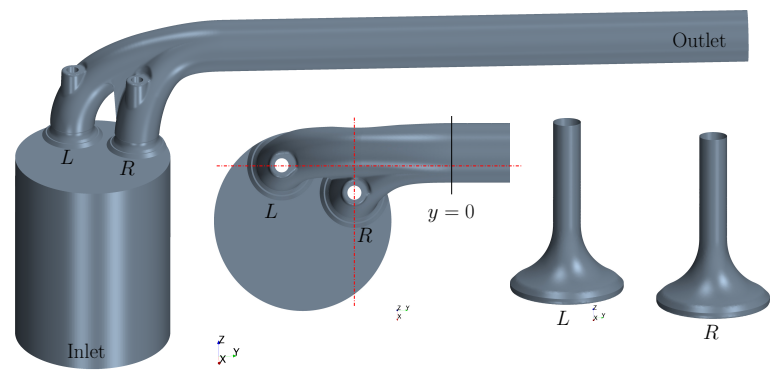

Figure 3: The exhaust port geometry.

valve port, as shown in Fig. 3 Further, two plane locations are indicated by dash-doted lines cutting the valve ports in the top view, where the simulation data will be shown.

Different numerical setups are considered to model the gas outtake process from the cylinder, where a summary of the cases is listed in Tab. 2. A "hot" flow bench experiment is mimicked replacing the moving piston by a constant total pressure or constant mass flow rate boundary condition and considering a fixed valve lift of $5 \mathrm{~mm}$. The total pressure boundary condition value and the mass flow rate boundary condition value at the inlet are selected to reassemble the flow conditions occurring when the motion of piston and valve are considered at this valve lift. A more sophisticated approach employs the piston movement and a valve motion during the exhaust cycle, where the piston lift motion is depicted in Fig. 4 (a). The initial valve opening each exhaust cycle is $3.5 \mathrm{~mm}$, the complete valve opening and closing phases not being modeled.

To differentiate the flow effects induced by the motion of the piston and the valves, a case with piston and limited valve motion is studied. Thereby, the initial valve motion from $3.5 \mathrm{~mm}$ to a maximum valve lift limit of 5 $m m$ is considered. The limited valve lift curve is shown 


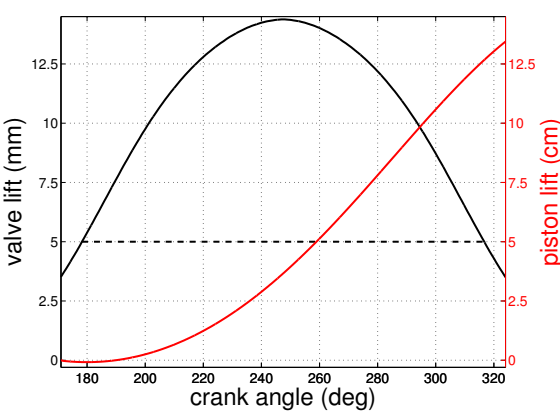

(a) piston and valve motion curves

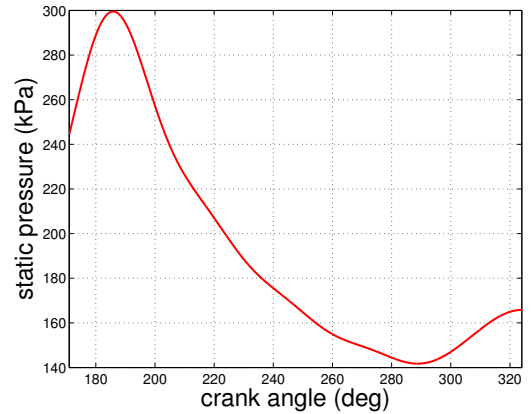

(b) static pressure at the outlet

Figure 4: The curves describing the motion of the piston and the valve are plotted in (a). The static pressure distribution at the exhaust port outlet as a function of the crank angle is shown in (b).

Table 2: Overview of the four investigated cases.

\begin{tabular}{|c|c|c|c|}
\hline Case & $\begin{array}{l}\text { Piston motion or Inlet } \\
\text { boundary condition }\end{array}$ & Valve & $\begin{array}{l}\text { Static Pressure Outlet } \\
\text { boundary condition }\end{array}$ \\
\hline $\mathrm{I}$ & $=430 \mathrm{kPa}$ & fix & const. $p_{s, c}$ \\
\hline II & const. $\dot{m}_{i n}=0.32 \mathrm{~kg} / \mathrm{s}$ & fixed at $5 \mathrm{~mm}$ & const. $p_{s, \text { out }}=282 \mathrm{kPa}$ \\
\hline III & & limited to $5 \mathrm{~mm}$ & e $p_{s, \text { out }}$ \\
\hline IV & moving piston & moving valves & variable $p_{s, \text { out }}$ \\
\hline
\end{tabular}

as dashed line in Fig. 4 (a).

A flow bench experiment is commonly performed at room temperatures. However, for the present simulations, the boundary conditions are chosen to mimic engine-like conditions. Hence, the in-cylinder temperature is $1090 \mathrm{~K}$. The piston surface and the cylinder walls are cooled and therefore a constant temperature boundary condition of $600 \mathrm{~K}$ and $400 \mathrm{~K}$, respectively, is applied to the components. The temperature variations at the exhaust port walls are small $(\sim 10 K)$ compared to the occurring temperature differences. This allows to set constant temperature boundary condition of $500 \mathrm{~K}$ at the exhaust port walls [2].

A conventional turbocharger turbine causes a resistance for the incoming exhaust flow from the engine cylinder, which in turn induces a back pressure at the exhaust port outlet. The back pressure can be regulated through a waste gate. Therefore, the static pressure at the exhaust port outlet is not constant, but dependent on the engine components downstream. The static pressure applied at outlet boundary was obtained by one-dimensional engine simulations [17, 18] for a similar engine configuration, which have been validated with experimental measurements. This sequence is plotted in Fig. 4 (b) as a function of the crank angle. For the cases neglecting the motion of the piston, a con- stant static pressure $282 \mathrm{kPa}$ at the exhaust pipe outlet is imposed, which corresponds to the static pressure for a valve lift of $5 \mathrm{~mm}$ or an equivalent crank angle of $178^{\circ}$ in the one-dimensional sequence imposed for the cases considering the piston motion. For the constant total pressure inlet boundary condition case, a stagnation pressure of $430 \mathrm{kPa}$ has been applied at the inlet and for the constant mass flow rate inlet boundary condition case, a mass flow rate of $0.32 \mathrm{~kg} / \mathrm{s}$ has been employed. These values have been obtained from case considering the motion of the piston and the valves at a valve lift of $5 \mathrm{~mm}$.

Considering the motion of the piston and the valves, the simulations are performed in a cyclic approach. At each beginning of a cycle, the pressure and the temperature distributions are reset to the initial cycle values in the cylinder of $500 \mathrm{kPa}$ in the cylinder and $282 \mathrm{kPa}$ in the exhaust port, and $1140 \mathrm{~K}$ in the cylinder and $800 \mathrm{~K}$ in the exhaust port, respectively. The cylinder pod top has been chosen to distinguish between the in-cylinder and exhaust port region. The entire velocity field is transferred from the previous cycle end to the next cycle start. The flow velocities at the end of an exhaust cycle are low compared to the flow velocities occurring at the beginning of the exhaust cycle. Hence, the mapping of the velocity field can be seen as a perturbation to the 
cycle solution to provide an independent initial condition. The averaged data shown is sampled over twelve exhaust cycles.

\section{Simulation Procedure}

The governing equations for a compressible flow (i.e. mass, momentum, and energy) have been simulated for the exhaust port geometry using a commercial solver, StarCCM+ by CD-adapco, based on the finite volume approach. For the conservation of the fluid momentum at time $t$, the Navier-Stokes equations in the three dimensions $x_{i}, i \in\{1,2,3\}$ are solved,

$$
\frac{\partial\left(\rho u_{i}\right)}{\partial t}+\frac{\partial\left(\rho u_{i} u_{j}\right)}{\partial x_{j}}=-\frac{\partial p_{s}}{\partial x_{i}}+\frac{\partial \sigma_{i j}}{\partial x_{j}},
$$

where $\rho$ is the fluid density, $u$ is velocity, $p_{s}$ is static pressure, and $\sigma$ is the viscous stress tensor. The viscous stress tensor for a Newtonian fluid can be written as,

$$
\sigma_{i j}=\mu\left(2 S_{i j}-\frac{2}{3} S_{k k} \delta_{i j}\right)
$$

where

$$
S_{i j}=\frac{1}{2}\left(\frac{\partial u_{i}}{\partial x_{j}}+\frac{\partial u_{j}}{\partial x_{i}}\right)
$$

$\delta$ is the Kronecker-delta function, and $\mu$ is the dynamic viscosity. The equation of mass conservation can be written as,

$$
\frac{\partial \rho}{\partial t}+\frac{\partial\left(\rho u_{i}\right)}{\partial x_{i}}=0 .
$$

The energy conservation equation in terms of the specific total energy $e_{0}$ is,

$$
\frac{\partial\left(\rho e_{0}\right)}{\partial t}+\frac{\partial\left(\rho e_{0} u_{j}\right)}{\partial x_{j}}=-\frac{\partial\left(p_{s} u_{j}\right)}{\partial x_{j}}-\frac{\partial q_{j}}{\partial x_{j}}+\frac{\partial\left(u_{i} \sigma_{i j}\right)}{\partial x_{j}},
$$

where $q$ is the heat flux, which is solved by Fourier's law. The gaseous media streaming out of the cylinder is assumed to be air and the ideal gas law is used to link temperature, pressure and density. The isentropic exponent $\gamma$ is 1.4. The relation of the specific total energy and the static pressure, fluid density and flow velocity is given by,

$$
e_{0}=\frac{p_{s}}{\gamma-1}+\frac{1}{2} \rho u^{2}
$$

In the current problem setup, a high Reynolds number results due to the high flow velocities in the port. Hence, a fine mesh grid is required to resolve the entire range of turbulent scales. This would result in an excess of computational resources, since the study focuses on the global flow phenomena occurring in the exhaust port. For the present case, the large scale structures are dictating the main properties of the flow, and are governed by the geometrical constrains and the imposed boundary conditions. The highest amount of kinetic energy is carried by the large flow structures and the kinetic energy is transferred to the small scales through the $-5 / 3$ turbulent energy cascade. At the smallest flow scales, the kinetic energy is dissipated due to molecular interactions into heat. At a distance from walls, this behavior is universal and can be consequently modeled. In order to resolve the significant energetic flow structures, a large proportion of the inertial subrange in the turbulent spectra is resolved and the flow scales smaller than the mesh discretization are modeled. This numerical approach is commonly known as Large Eddy Simulation (LES). The unresolved terms are the so-called subgrid scale terms, which are responsible for the dissipation of kinetic energy. Modeling assumptions can be used to reassemble the behavior of the small scales. However, for the current application no global valid assumptions can be made. Nonetheless, the discretization schemes induce an intrinsic diffusive error, which can be used to dissipate the necessary amount of kinetic energy at the smallest scales. Here, these subgrid scale terms are handled implicitly by the inherent dissipation of the numerical solver.

For time advancement, a second order accurate implicit scheme is employed, which uses an algebraic multi-grid method and a constant time step of $1 \cdot 10^{-7}$ $s$. A second order bounded central-difference scheme is used for spatial discretization to guarantee boundedness and high numerical accuracy [19]. The normalizedvariable diagram value is computed based on the local flow variables to determine the amount of upwindblending to stabilize the central difference scheme when required [20]. Fureby and Grinstein [21] show that this kind of discretization schemes are suitable for implicit LES calculations.

\subsection{Computational grids}

The numerical mesh grids used in the simulations are equipped with a hexahedral core-mesh (approximately $0.6 \mathrm{~mm}$ ) and two prism layers towards the walls. The prism layers at the wall extend over a thickness of 0.3 $\mathrm{mm}$ in the entire flow domain. Since the wall boundaries are not fully resolved, a wall function approach 
has been employed. In the last part towards the exhaust pipe outlet, grid stretching has been applied to support the numerics propagating the structures smoothly out of the domain and to avoid spurious reflections. Initial grid stretching is applied in the cylinder to support a reasonable cell quality when the cylinder volume is compressed by the piston.

The modeling of the piston and the valve motion requires the deformation of the numerical grid. The Arbitrary Lagrangian-Eulerian (ALE) method is utilized to achieve a fully conservative discretization of the governing equations on the moving computational mesh [22, 23].

A grid sensitivity study has been performed by Wang et al. [15] for a cold case setup, and the compared line plots of velocity magnitude and turbulence kinetic energy revealed minor differences. Additionally, the comparison of the spectra obtained at the same probe locations on the three grids demonstrated the applicability of the implicit LES approach. The numerical results of the global parameters were validated with experimental measurements within an error range of less than $2 \%$. Further validation and verification has been summarized by Wang [24]. With engine-like hot boundary conditions, the velocities occurring in the exhaust port are higher. Nevertheless, the viscosity of the medium is increased due to the higher temperatures. Thus, the resulting Reynolds numbers for the two case setups are similar. Further, the used solver has been successfully employed to simulate similar flows in engineering applications and has been validated with Picture Image Velocimetry (PIV) measurements and experimentally obtained performance measurements [25].

\section{Results}

The simulation results are presented in this section. First, the flow field in the exhaust port geometry with fixed valve lift is described and in the following section, the flow field changes due to piston and valve movement are analyzed. Finally, the consequences of the valve and piston motion on the discharge coefficient and the total pressure drop between the cylinder and the exhaust are elucidated.

\subsection{Flow Field with static boundary conditions}

The flow field in the exhaust port at laboratory conditions has been described by Wang et al. [15] and this study has been extended to pulsatile flow conditions by Semlitsch et al. [16]. However, in contrast to these previous studies, the present analysis treats engine-like hot conditions. Two cases with a mass flow rate and a total pressure inflow boundary condition have been computed at a fixed valve lift, where the values for the total pressure and the mass flow rate have been obtained from the moving piston moving valve case, when a valve lift of $5 \mathrm{~mm}$ is reached. The fixed valve lift of $5 \mathrm{~mm}$ corresponds to a non-dimensional valve lift $L_{v} / D_{v}$ of 0.12 , which falls in the first exhaust port flow regime defined by Annand and Row [13]. Hence, the flow at this low valve lift is expected to be confined to a conical jet through the narrow valve gap.

The flow field in terms of the Mach number for the constant mass flow rate inlet and the constant pressure inlet cases are shown in Fig. 5. (a) and (b), respectively, where the plane locations with respect to the geometry are shown in Fig. 3. At low valve lifts, the valve and the valve port form together a Venturi shape, wherein the flow is accelerated in the convergent section. At the narrowest cross-section, the highest flow speeds are reached and a conical jet-like structure contracting towards the valve stem forms. The valve ports exhibit a large divergence angle downstream of the valve seat and therefore, flow separation occurs at the outer circumferential walls. The flow separation of the conical jet-like structure is accompanied by recirculation zones, as described by Caton and Heywood [2]. The jet contracts towards the valve stem, which causes the formation of Görtler-vortical flow structures at the valve head. The stream follows the valve stem up towards the exhaust port walls. There, the jet-like structure is deflected into the direction of the exhaust pipe.

Figure 5 shows that the flow velocities are higher in the $R$ valve port than in the $L$ valve port. There are several reasons for the increase of the mass flow rate in the $R$ valve port. Since, the flow in the $L$ valve port requires to cover a larger distance to reach the exit pipe, the pressure gradient is slightly lower in the $L$ valve port than in the $R$ valve port. Further, the stream through the $R$ valve port represents (due to the higher flow momentum) a blockage in the junction region for the stream flowing through the $L$ valve port. This blockage acts as a resistance and therefore, a higher back pressure for the flow originating from the $L$ valve port.

The exit pipe axis and the valve ports are misaligned and therefore a swirling motion in the exit pipe is expected. However, the streamline visualization shown in Fig. 6 illustrates that the main stream from the valve ports hit the top of the exhaust port walls and flows foremost relatively straight towards the exit pipe. In the $R$ valve port, the conical jet follows the valve stem towards the top wall, where the jet is deflected into the exit pipe. The annular jets cause inherently fluid en- 


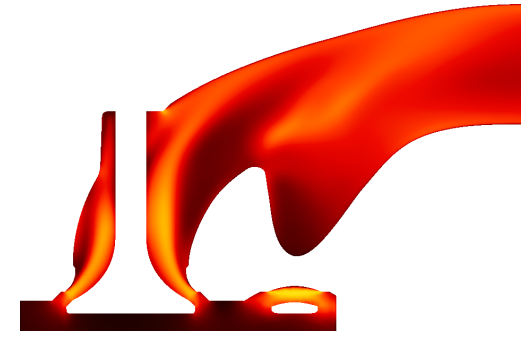

$L$ valve port

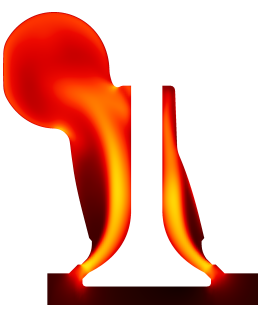

$R$ valve port (a) constant mass flow rate

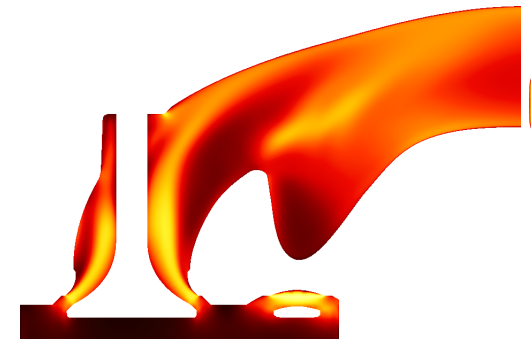

$L$ valve port

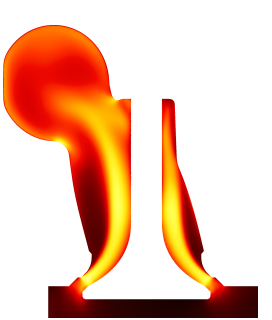

$R$ valve port (b) constant total pressure

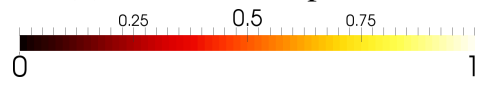

Figure 5: The time averaged Mach number (-) contours for the fixed valve, constant mass flow rate and constant total pressure boundary condition case.

trainment, which drains fluid from the ports into the exit pipe. Thereby, a low static pressure zone is generated in the $R$ valve port surrounding the annular jet (see Fig. 7), which stretches upwards to the lower region of the exit pipe. Further, Fig. 7 shows that the static pressure in the $R$ valve port is lower than in the $L$ valve port. Nevertheless, due to the blockage of the flow from the $L$ valve port, the flow is redirected around the high momentum flow from the $R$ valve port and streams towards the low pressure region, which is illustrated in Fig. 6 This change of flowing direction induces the helical motion in the exhaust pipe. Figure 6 shows that the strong helical motion is initiated beneath the stream rising out of the $R$ valve port. Inspecting Fig. 6 showing streamlines initiated separately in the individual ports, it can be observed that streamlines emitted in the $L$ valve port propagate even into the $R$ valve port. The lower static pressure in the $R$ valve port induces the higher flow velocities in the $R$ valve port.

The flow field resulting from the two constant inflow boundary conditions, employed for the fixed piston and fixed valve, is quantitatively similar. Nevertheless, the flow speeds resulting from the mass flow rate inflow boundary condition are lower than the flow velocities in-
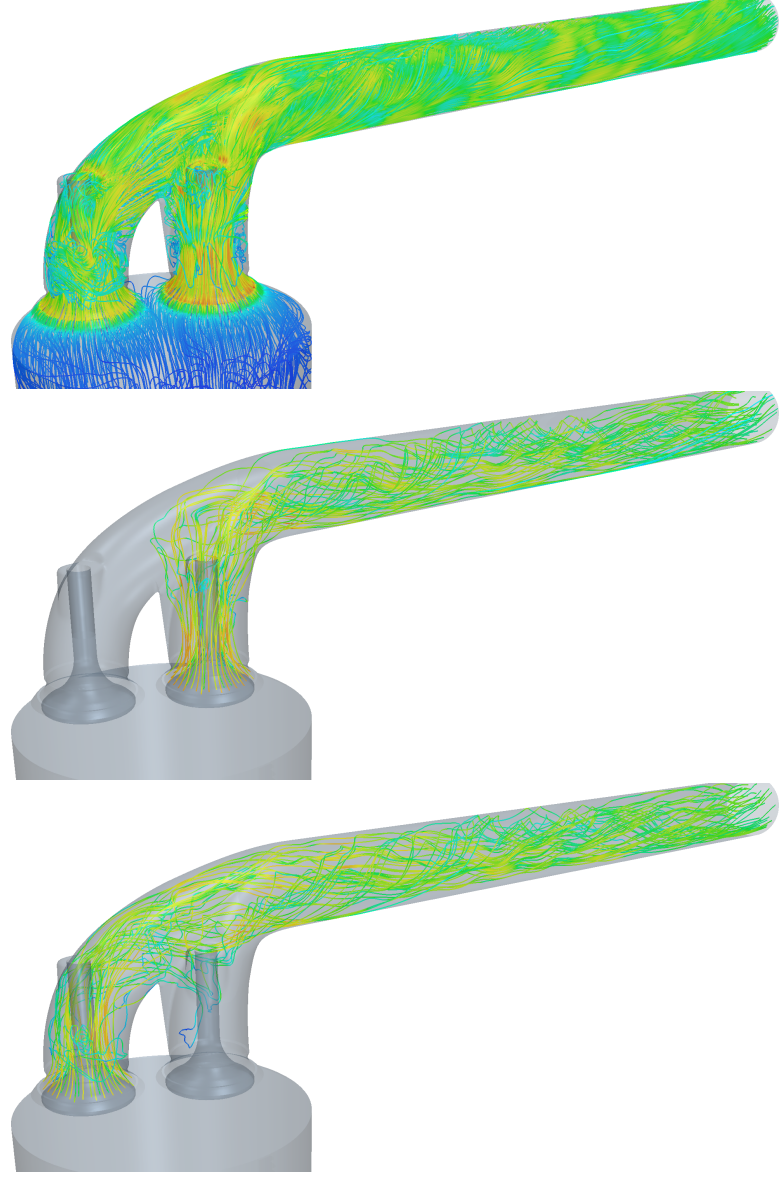

Figure 6: The streamline visualization colored by the velocity magnitude in the exhaust port geometry illustrates the strong helical motion generation. For the plots at the mid and the bottom, the streamlines are emitted in the individual valve ports.

duced by the total pressure inflow boundary condition, which is shown in Fig. 5. The Mach number reached with the total pressure inflow boundary condition are close to unity, while for the mass flow rate boundary condition, the peak Mach number remains below 0.8 .

\subsection{Flow field with piston motion}

Considering the piston and valve motion in the simulation approach, the flow field develops differently due to its pulsatile nature and the evolution of two distinct flow regimes. The simulations start with a valve opening of $3.5 \mathrm{~mm}$ at a crank angle of $171^{\circ}$. Initially when the valves open, a pressure pulse propagates through the exhaust port and a high velocity stream develops in the narrow gap. Right downstream of the valve seat, strong outward flow recirculations (away from the valve stem) can be observed for a crank angle of $175^{\circ}$, which are shown in Fig. 8 (a). This results in strong shedding flow 


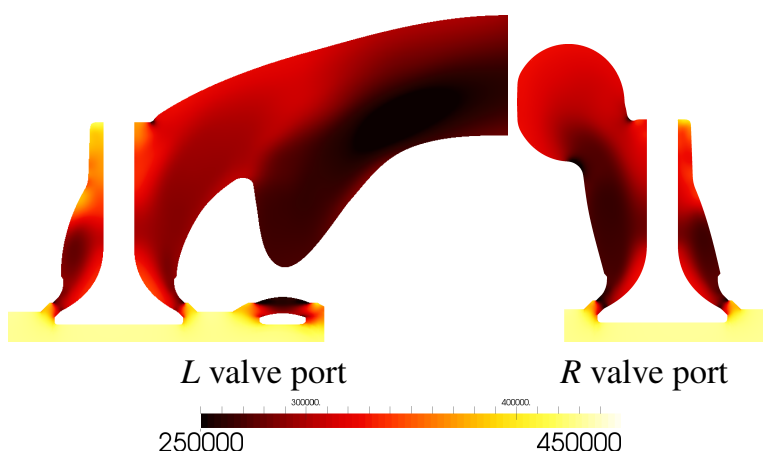

Figure 7: Time averaged static pressure $(\mathrm{Pa})$ contours for the fixed valve, constant total pressure boundary condition case.

motion of the annular stream along the valve stem and chaotic flow motion in the valve port. This chaotic motion in the valve port acts as feedback to the conical jet flow evolution and inhibits the initial development of an annular jet streaming up the valve stem. The smallest effective cross-section is generated between the valve head and the valve seat.

As shown in Fig. 8(b) for a valve lift of $5 \mathrm{~mm}$ corresponding to a crank angle of $178^{\circ}$, the Mach number is significantly decreased compared to the Mach numbers resulting with fixed valve lift and constant inlet boundary conditions, which are shown in Fig. 5 at the same scales. At this valve lift, a conical jet contracting towards the valve stem can be seen in Fig. 8(b).

Figures 8 (c) illustrates the typical flow field at large valve lifts. Hence, the ratio of valve lift to valve diameter is larger than 0.2. For these valve lifts, the smallest effective cross-sectional area is not the cross-sectional area in between the valve seat and the valve head, but the area in between the valve port and the valve stem is the smallest effective cross-sectional area. The flow accelerates at the walls due to the Coanda-shaped valve port entrance, while lower flow velocities result at the center of the valve port due to the flow blockage caused by the valve. The flow separates from the valve head at large valve lifts. The extent of the recirculation regions at the valve port walls decrease with increasing valve lift. Slightly after the maximum valve lift is reached at a crank angle of $250^{\circ}$, the recirculation regions at the valve port entrance diminish nearly entirely. At high valve lifts, the highest flow velocities occur in the junction region, where the two streams merge. The flow velocities at these valve lifts are significantly higher in the $R$ valve port than in the $L$ valve port when valve motion is considered.

With the valves closing, the recirculation regions at the valve port walls start to appear again (see Fig. 8(d))

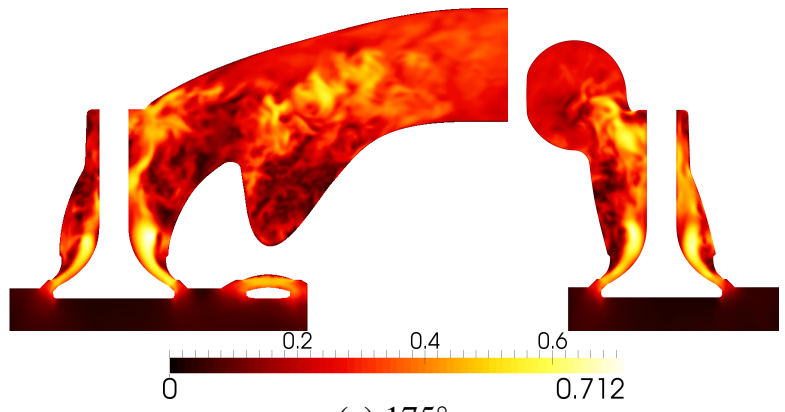

(a) $175^{\circ}$

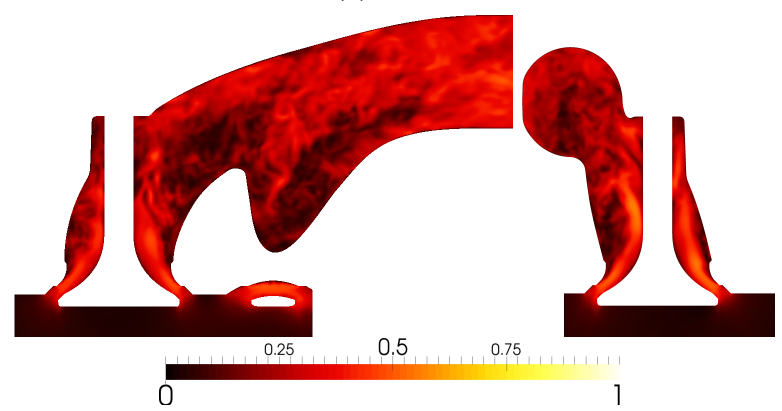

(b) $178^{\circ}$

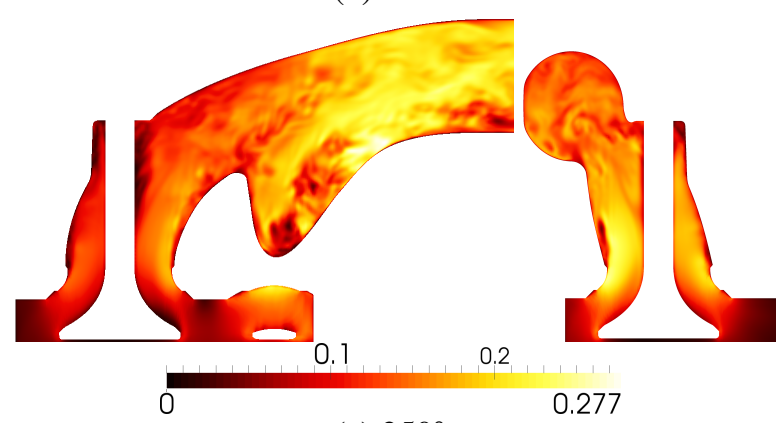

(c) $250^{\circ}$

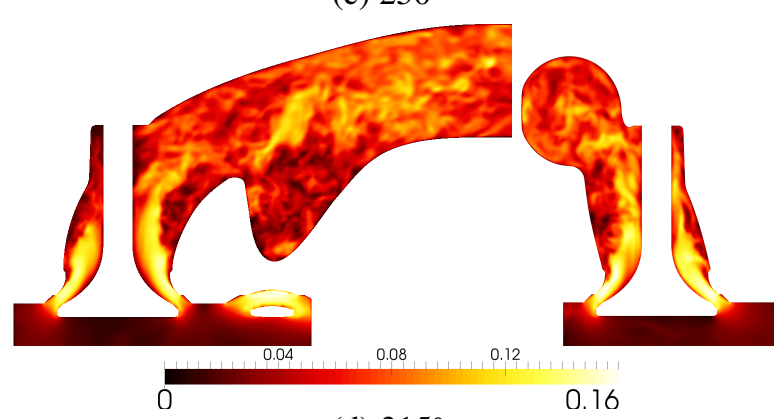

(d) $315^{\circ}$

Figure 8: The instantaneous Mach number contours at different crank angles with valve and piston motion.

and the extent of the recirculation zones increases continuously as the valve lift decreases. The smallest crosssectional area for the flow shifts towards the gap generated between the valve head and the valve seat. The flow speeds at the end of the exhaust cycle are rather 
low compared to the flow velocities occurring in the beginning of each exhaust cycle. Although, the valve lifts shown in Fig. 8(b) and Fig. 8(d) are the same, the streams in the valve ports exhibit different flow features, since the pressure gradients over the exhaust port are different. For example, the conical jet exhibits a larger spreading rate at $315^{\circ}$ as compared with the situation observed at $178^{\circ}$ when separating from the exhaust port wall towards the end of the exhaust cycle.

The footprints of the initial pressure pulse propagating through the system with moving geometry influences the flow field. Streamline visualizations at different crank angles in the exhaust cycle with moving valves are shown in Fig.9 The helical motion of the flow in the exit pipe is primary provoked by the low pressure distribution in the $R$ valve port, which is shown in Fig. 7 Figure 9 (a) illustrates that after the initial pressure pulse rushed through the exhaust ports, the helical flow motion in the exit pipe vanishes and straight streamlines
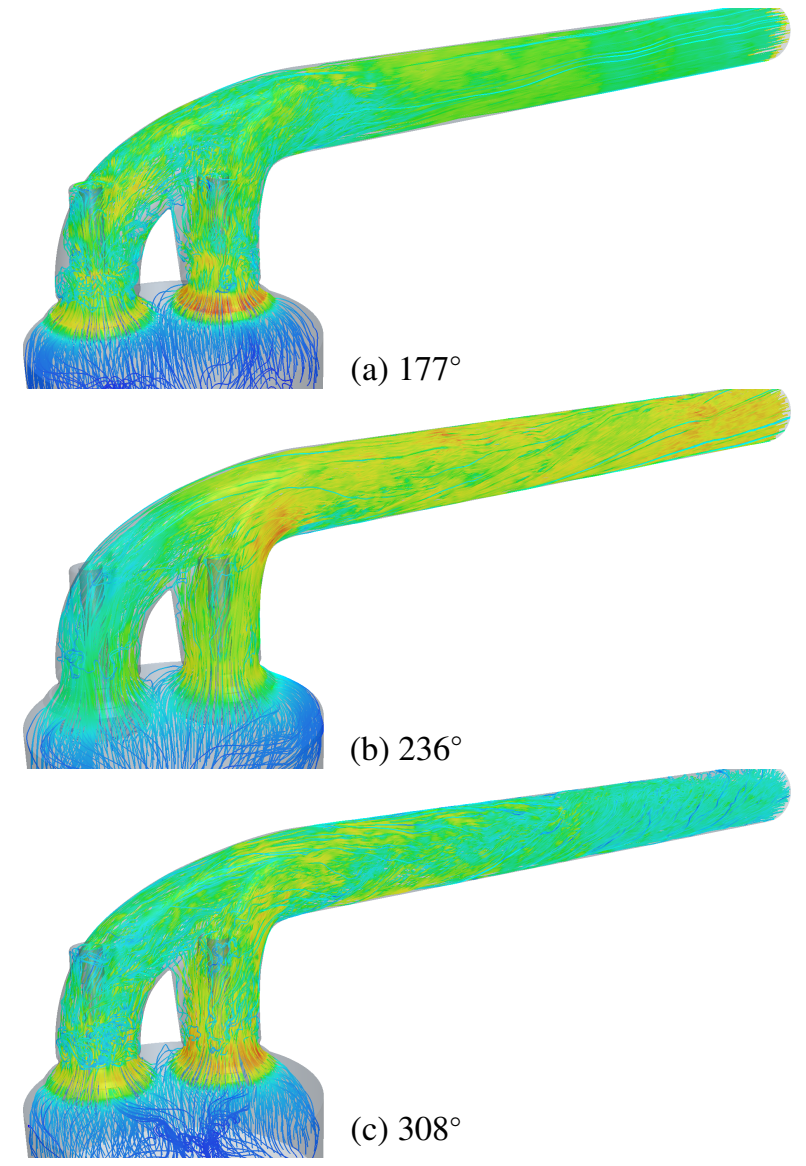

Figure 9: Streamline visualizations colored by the velocity magnitude show the flow structures in the exit pipe with valve and piston motion. manifest. A time span would be required until the flow field reaches a quasi equilibrium state between the two valve port streams and a low static pressure region in the proximity of the $R$ valve port could develop, which is similar to the flow field for the constant inlet boundary condition case. With the case of limited valve lift motion, the flow requires about $10-15$ crank angle degrees until such a quasi equilibrium state is reached when the valve motion is stopped. With this quasi equilibrium state, a higher mass flow streams through the $L$ valve port. When the valve motion is not limited, a quasi equilibrium state is not reached during the entire blow down pulse and the amount of swirling in the exit pipe varies throughout the entire cycle, as e.g. shown for a crank angle of $236^{\circ}$ in Fig. 9](b). However, a similar helical motion as for the cases of constant inflow conditions is not reached when the valve lift is regarded. At large valve lifts, the development of larger flow recalculation zones in the valve port is not realizable and therefore, a low static pressure region cannot establish. Nonetheless, towards the end of the exhaust cycle when the valve lift is decreased, a low pressure region develops and Fig. 9 (c) shows that a helical motion in the exit pipe evolves.

\subsection{Flow statistics}

The cycle averaged parameters for the cases treating the piston motion are plotted in Fig. 10, limiting the valve motion, and in Fig. 11, considering the valve motion. The monitored pressure histories are shown in the top plot of the figures. The in-cylinder total pressure decays initially rapidly and exhibits a nearly constant decay rate until a crank angle of $220^{\circ}$. Further, the total pressure decays until a crank angle of about $290^{\circ}$ at a lower rate. Finally, the total pressure in the cylinder increases since the piston motion causes a compression in the cylinder and the employed outlet boundary condition sequence increases the static pressure at the outlet towards the end of the exhaust cycle, as shown in Fig. 4 (b). The static pressure monitored in the gap between valve head and valve seat of the individual valve ports increases initially rapidly, since the pressure responds rather fast. In this early stage of the exhaust cycle, the static pressure sequences exhibit remarkable oscillations due to transient flow phenomena. After a crank angle of about $190^{\circ}$ the static pressure reaches values similar to the in-cylinder total pressure and follows the shape on the in-cylinder total pressure decay. Until a crank angle of $220^{\circ}$ fluctuations in the static pressure can be observed in Fig. 10. Thereafter, the fluctuations remain, but are too small to be distinguishable in the 

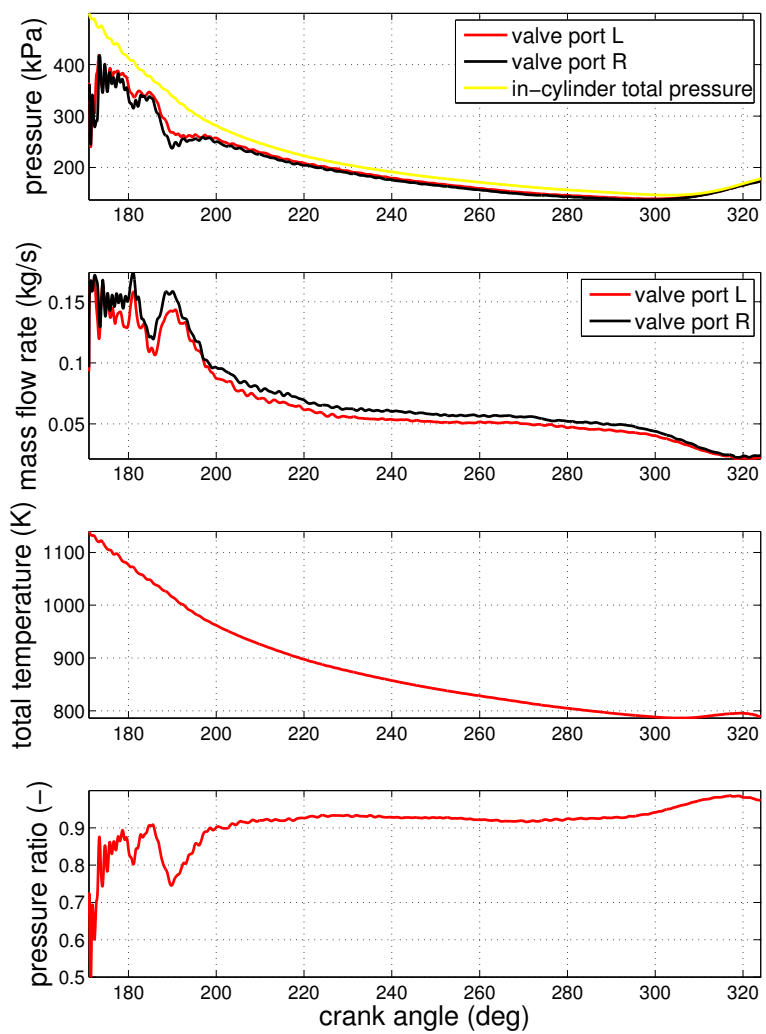

Figure 10: Cycle averaged pressure, mass flow rate, and temperature sequences are shown as a function of the crank angle for the moving piston and fixed valve case.

plot. Figure 10 and Fig. 11 show that the pressure histories between the cases limiting and considering valve motion exhibit a similar behavior. However, limiting the valve lift restricts the pressure energy leaving the cylinder and therefore, the difference between the incylinder total pressure and the static pressures in the gaps is higher for this case.

The interaction of the streams in the junction section has been described in the previous section. The disparity of the two individual port geometries leads to a variation of the mass flow rates developing through the valve ports. The pressure gradient is lower for the $L$ valve port due to the longer distance from the cylinder to the exhaust port outlet as compared with the $R$ valve port. Further, the faster stream originating from the $R$ valve port blocks the passage in the junction region for the less momentum containing stream coming from the $L$ valve port. These two factors lead to the different mass flow rates in the individual exhaust ports. However, the proportions of mass flow rates through the individual valve ports changes with the modeling approach. Using static inflow boundary conditions at a constant valve lift leads
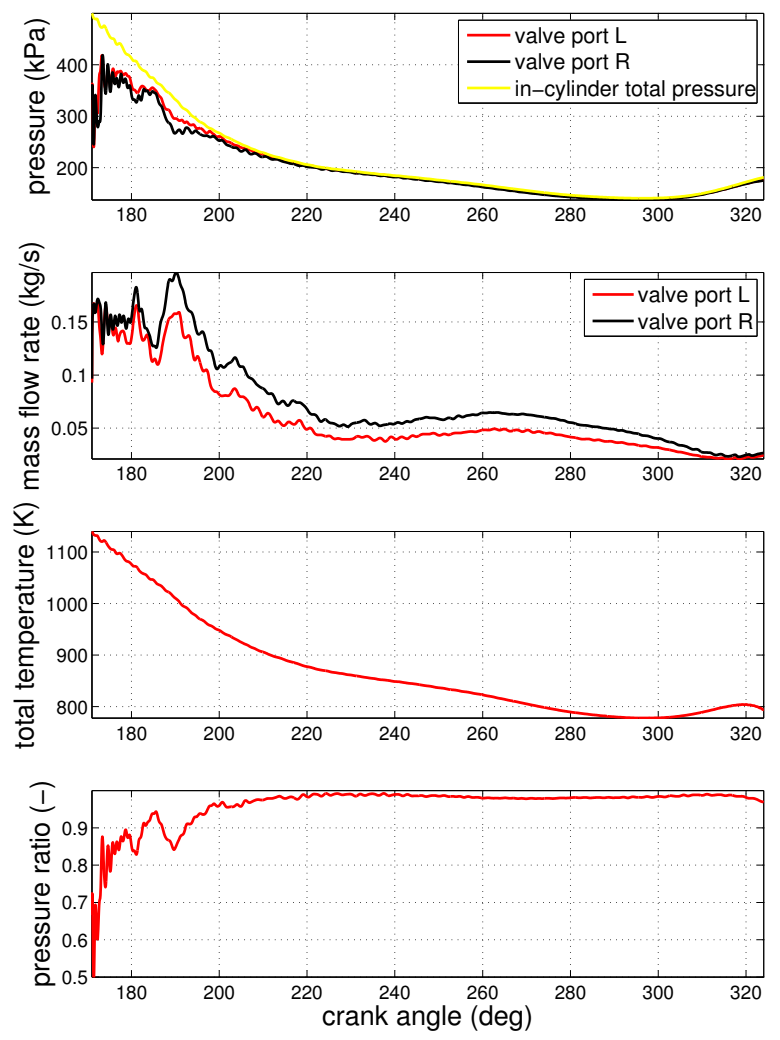

Figure 11: The cycle averaged parameters for the moving piston and moving valve case.

to a rather small difference in the mass flow rate between the valve ports. For the total pressure inlet boundary condition, $51 \%$ of the total mass flow streams through the $R$ valve port and for the mass flow inlet boundary condition $51.3 \%$ of the total mass flow rate run through the $R$ valve port. Figure 10 and Fig. 11 show quantitatively the mass flow rates through the individual valve ports and it can be observed that initially the mass flow rates develop nearly equally through the two valve ports. Large fluctuations can be observed in the mass flow rate history. At a crank angle of $187^{\circ}$ a local decrease followed by a peak in the mass flow rates at $190^{\circ}$ crank angle can be observed. Accounting for valve motion leads to higher maximal mass flow rates through the ports at this peak, as shown in Fig. 11. Further, the difference in the mass flow rates through the individual valve ports is larger considering the motion of the valves than limiting the motion of the valves. This effect remains throughout the entire exhaust cycle. The limitation of the valve lift causes a reduced mass flow streaming out of the cylinder. After a crank angle of $220^{\circ}$, the mass flow rate remains rather constant until a crank angle of $295^{\circ}$ when 
the valve lift is fixed. However, the consideration of valve motion leads to lower mass flow rates at a crank angle of $230^{\circ}$, which increase again until a crank angle of $270^{\circ}$ due to the acceleration of the piston. For the limited valve lift case, the maximum difference of the mass flow rates is $10 \%$ and the average difference is $4.7 \%$. The average difference in the mass flow rates through the individual valve ports over the exhaust cycle is increased to $12 \%$ and the peak difference is $18.2 \%$.

The sequence of the total temperature over the exhaust cycle behaves similar for the limited valve motion case and moving valve case. Nonetheless, at a crank angle of approximately $210^{\circ}$ the total temperature in the cylinder is slightly lower for the moving valve case compared to the fixed valve case, since the mass flow rates out of the cylinder are higher for the case with moving valve at that time. Therefore, the in-cylinder total temperature remains lower for the moving valve case, but the total temperature curve decreases with a shallower slope compared to the static valve case. For the moving valve case, the mass flow rate reaches a local minimum at a crank angle of about $235^{\circ}$ and increases slightly until a crank angle of approximately $265^{\circ}$. Due to this increase in the mass flow rate for the moving valve case, the in-cylinder total temperature decrease is augmented and reaches a minimum before a crank angle of $300^{\circ}$. However, for the static valve lift case, the mass flow rate decreases monotonically and therefore, the in-cylinder total temperature decreases at the same rate. As a consequence, the minimum of the in-cylinder total temperature is reached after a crank angle of $300^{\circ}$, where the minimum value is higher than for the moving valve case. Towards the end of the exhaust cycle the mass flow rate diminishes and the in-cylinder total temperature increases slightly for both cases. At the end of the cycle, the in-cylinder total temperature is higher for the fixed valve lift case compared to the moving valve case. Similar shapes of the flow parameters as for the moving valve case have been measured and reported by Caton and Heywood [2] in their experimental work.

\subsection{Flow and discharge coefficient}

The flow and discharge coefficient intend to describe the same governing phenomena, i.e. the ratio of the real mass flow rate to the ideal mass flow rate. However, the formulation of the reference area is different. For the flow coefficient, the reference area is fixed to the outer valve head area $D_{v}^{2} \pi / 4$, whereas for the discharge coefficient, the valve curtain area is considered as reference area. The valve curtain area is varying linearly with the valve lift, while the valve head area is a constant. For the simulations considering a fixed valve lift, the choice between the two reference areas change only the magnitude of the calculated coefficient. Since only one operation point is considered for the fixed valve lift cases, a change on the shape of the coefficient progression cannot be captured. Nevertheless, the progression of the flow and discharge coefficient obtained by flow bench measurements has been compared by Algieri [10]. The flow and discharge coefficient for the current case accounting for valve and piston motion is shown in Fig. 12. It shows the same trends as observed by Algieri [10] experimentally. The discharge coefficient is high at small valve lifts and low at large valve lifts, while the flow coefficient is low at small valve lifts and high at large valve lifts. Although the flow velocities are not similar at the beginning of the exhaust cycle compared to the end of the exhaust cycle (as shown in Fig 8), the flow and discharge coefficient are approximately symmetric when the valve moves downwards and upwards.

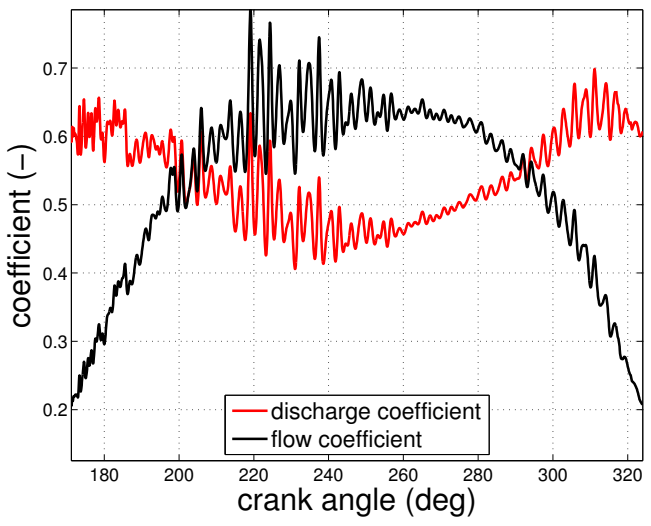

Figure 12: The flow and discharge coefficient are contrasted for the moving valve and moving piston case.

The large discharge coefficient fluctuations (shown in Fig.12) for the cases accounting for piston motion result due to the last term in Eq. 1. Figure 10 and Fig. 11. show that the ratio of the static pressure $p_{s}$ in the valve port gap to the total pressure in the cylinder $p_{0}$ is at certain parts of the engine cycle close to unity. It is expected that these fluctuations disappear with more cycles used for averaging.

A more accurate formulation of the smallest effective cross-sectional area would allow to relate the real mass flow rate to an efficiency of the valve port geometry, since the ideal mass flow rate is more accurately approximated and thus a physical interpretation of the coefficient would be possible. However, the real smallest effective cross-sectional area is difficult to determine, due to presence of flow separation and due to the complex shape of the geometry. For the present geometry, 
the smallest effective cross-sectional area is determined at small valve lifts by the gap between valve head and valve seat. Nonetheless, at larger valve lifts, the smallest effective cross-sectional area is governed by the minimum inner cross-section of the valve port subtracted by the valve stem cross-section (see Fig. 1). The transition between the two regimes occurs at a crank angle of about $186.6^{\circ}$ corresponding to a valve lift of about $6.9 \mathrm{~mm}$, which results in a valve lift $L_{v}$ to valve head $D_{v}$ ratio of about 0.17 . Figure 12 shows that the discharge coefficient starts dropping at this range. Annand and Row [13] quoted that this transition range occurs at a ratio $L_{v} / D_{v}$ of about 0.2 . Figure 8 illustrates the two flow regimes, where a conical cylindrical jet contracts towards the valve stem and where an annular jet forms.

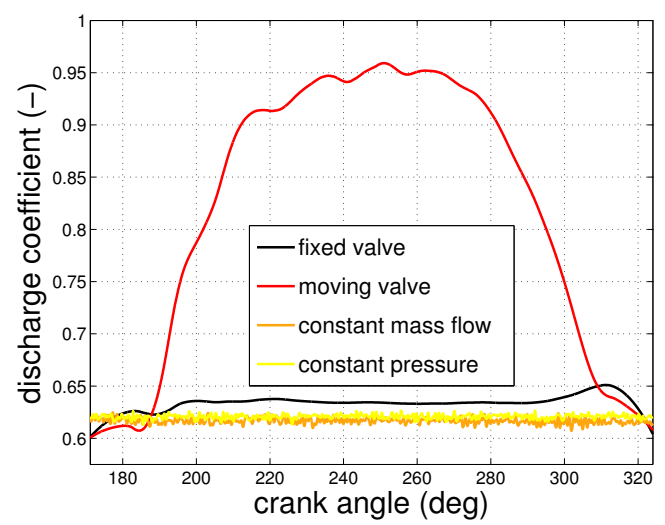

Figure 13: The discharge coefficient $C_{D}$ is compared for all the investigated approaches. Note that the considered reference area is different from that used in association with Fig. 12

Figure 13 shows the collected discharge coefficients for all simulated cases. The reference area used for the calculation of the coefficient for the valve and piston motion case is the valve curtain area limited to the minimal cross-sectional area given by the inner crosssection of the valve port subtracted by the valve stem cross-section. A lower coefficient value results at low valve lifts, whereas the coefficient value is high at the large valve lifts. The obtained discharge coefficient for the constant inflow boundary conditions are similar and exhibit only small fluctuations (less than one percent), as shown in Fig. 13. When the valve lift is limited to a maximum valve lift of $5 \mathrm{~mm}$, the discharge coefficient exhibits large fluctuations, while the valves are opening. Thereafter, the discharge coefficient remains rather constant with small fluctuations. For this case, the discharge coefficient is slightly higher than for the constant inflow boundary condition cases.

The total pressure drop sequence normalized by the according in-cylinder total pressure for the three simulation approaches is show in Fig. 14 The total pressure drops resulting for the steady total pressure and continuous mass flow rate inflow boundary are nearly constant with only small variations over time. The total pressure drop for the two approaches applying constant inflow boundary conditions result to be different, although the discharge coefficient are nearly equal, see Fig. 13 . However, Fig. 5 showed that the flow velocity magnitudes resulting with the two different boundary conditions are different. Therefore, the total pressure drops are expected to be different.

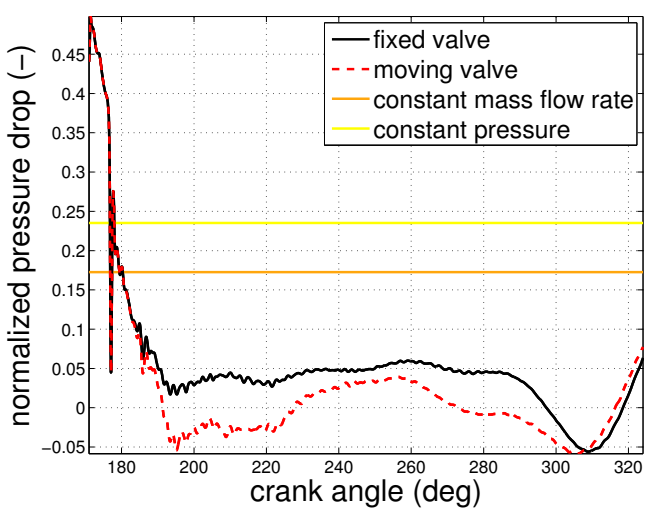

Figure 14: Total pressure drop between the cylinder and the outlet normalized by the in-cylinder total pressure for the different simulation approaches.

When valve and piston motion are regarded, the total pressure drop generated at small valve lifts is initially high and decays very rapid. This shape establishes since the in-cylinder total pressure is initially high and decreases instantly. A sharp drop indicating a short sudden decay in the total pressure drop occurs when the first pressure wave, containing a high total pressure, reaches the monitoring plane. At a crank angle of about $184^{\circ}$, the valve lift reaches $5 \mathrm{~mm}$ and there, the cases considering the piston motion separate, since the motion of the valve is locked for the limited valve lift case. For the limited valve lift case, the in-cylinder total pressure cannot decrease as rapid as for the case where further valve opening is considered. Further, the normalized pressure drop remains constant over a wide range of crank angles (at a value of about 0.05 ) when the valve is fixed at $5 \mathrm{~mm}$, since the decay of the in-cylinder total pressure is limited by the small valve gap. For the moving valve case, the total pressure is not restricted to decrease in the cylinder by the small valve gap and therefore a situation where the total pressure in the exhaust pipe is higher than the in-cylinder total pressure is provoked. 
With the initial blow down leaving the exhaust pipe, the total pressure drop becomes positive again. In the later development at a crank angle of about $295^{\circ}$ to $300^{\circ}$, the total pressure drop exhibits negative values for the both cases considering the piston motion. This decrease is initiated before the valve starts closing for the case, where the valve lift is limited to a maximal hight of 5 $\mathrm{mm}$. This decrease is not related to the valve motion, but to the increase of the static pressure boundary condition applied at the outlet, which is shown in Fig. 4(b).

\section{Conclusions and discussion}

The flow field evolution during the exhaust stroke of an internal combustion engine has been assessed by LES calculations with three different modeling scenarios. A case accounting for valve and piston motion has been contrasted with a case considering the piston motion and limited valve motion, and two cases treating a fixed valve lift of $5 \mathrm{~mm}$ and constant inflow boundary conditions mimicking the piston. Including valve and piston motion corresponds to a real engine case scenario, while the case modeling constant inflow boundary conditions at a constant valve lift intents to model a flow bench experiment performed at hot engine-like conditions.

For the cases assuming fixed valve lifts, the constant inflow boundary conditions were chosen accordingly to the mass flow rate and the total pressure values obtained from the case accounting for the valve and piston motion at $5 \mathrm{~mm}$ valve lift. However, the flow field results with higher velocity magnitudes, when the constant inflow boundary conditions are applied. The difference can be explained by the sharp mass flow rate and the total pressure gradients occurring at this valve lift for the case considering the valve and piston motion. Hence, the instantaneous values monitored within the case considering for the motion of valve and piston might not correspond exactly to the values evolving at this valve lift.

It was observed that for the investigated geometry, the interaction of individual valve port streams in the junction region plays an important role for the upstream flow field evolution in the ports. The stream through the valve port closer to the exit pipe represents a blockage in the junction region of the exhaust port for the stream arriving from the valve port further away. Hence, the arriving stream needs to flow around the blocking stream. With constant inflow boundary conditions, the flow field reaches there an equilibrium state, in which the mass flow rates through the individual valves differs marginally (few percent). With boundary conditions considering the motion of the piston and the valves, such an equilibrium between the two streams is not found. The two streams continuously interact with each other in the junction region, where the dynamics of the stream in the $R$ valve port hinder the stream from the $L$ valve port to develop a higher flow momentum. Therefore, the mass flow rates between the two ports differ by $12 \%$ in average and by $18.2 \%$ at maximum when valve and piston motion are considered. When the valve motion is limited to $5 \mathrm{~mm}$ and the piston motion is considered, the maximum difference in the mass flow rates is only $10 \%$ at maximum and $4.7 \%$ in average. Hence, the valve motion contributes to an unequal distribution of the mass flow rates through the individual valve ports. This interaction between two streams could also occur further downstream in the collecting manifold.

Although the flow field exhibits rather different flow features for the case considering valve and piston motion (at a valve lift of $5 \mathrm{~mm}$ ) compared to the cases where constant inflow boundary conditions at fixed valve lifts are applied, the discharge coefficient is only slightly effected. Limiting the valve lift motion to a maximum valve lift of $5 \mathrm{~mm}$ and considering the piston motion lead to a 1-2 percent higher discharge coefficient compared to the fixed valve lift and constant inflow boundary condition cases. Further, the discharge coefficient for the case remains constant over a wide range of crank angles. The small deviation of the discharge coefficients represents an error, which can be disregarded and the modeling assumption of neglecting for piston and valve motion seems to be valid in terms of the discharge coefficient value. However, the extension that the discharge coefficient represents qualitatively the flow does not seem to be correct, since the flow field exposes different flow structures for the distinguished cases although the discharge coefficients are similar for these cases.

Further, the same geometry has been investigated by Semlitsch et al. [16] assuming a fixed valve lift and boundary conditions accordingly to an air flow bench measurement. For such an experiment, the engine-like (i.e. hot and high pressure) boundary conditions are replaced by room ambient conditions and low pressure drops in order to facilitate the experimental procedure to measure the discharge coefficient. For constant inflow boundary conditions at the same valve lift, the simulations revealed the same discharge coefficient (the deviation is less than 1\%). Employing engine-like pulsatile inflow boundary conditions at a constant valve lift, a similar discharge coefficient was observed as for the limited valve motion case. Hence, the high temperatures and the high pressures do not have a significant 
influence on the observed discharge coefficient for the investigated valve lifts. At valve lifts below $3.5 \mathrm{~mm}$, supersonic flow effects are expected, which have not been observed for the considered valve lifts.

By neglecting the dynamic effects induced by the piston and valve motion, only a constant positive pressure drop can be measured. Nonetheless, with the introduction of the valve motion, a negative total pressure drop between in-cylinder and the outlet has been observed. An initial total pressure pulse propagates downstream, which leads to this negative pressure drop. When the valve lift is limited to a maximum of $5 \mathrm{~mm}$, the initial total pressure pulse cannot develop the same potential to cause a negative total pressure drop. Towards the end of the exhaust cycle, a negative total pressure drop occurs for both cases accounting for piston motion, since the time varying outlet boundary condition obtained from one-dimensional engine simulations rises in the static pressure. The negative total pressure drop represents an adverse pressure gradient, which compounds the gas expulsion process.

The commonly used formulation of the discharge coefficient based on the valve curtain area gives a high value at low valve lifts and a lower one at high valve lifts. Relating the discharge coefficient value with the actual efficiency of the port would suggest that the exhaust port geometry induces higher losses at large valve lifts, which is not the case. The formulation of the valve curtain area or the valve head area as the reference area in the discharge or flow coefficient lack in physical interpretability, since the minimal effective cross-sectional area enlarges initially with increasing valve lift, but at some valve lift, the minimal effective cross-sectional area is limited to the extents of the exhaust port geometry. This leads to two flow regimes developing during the exhaust cycle, a conical jet emerging between the gap formed by the valve head and the valve seat, which contracts towards the valve stem and a jet bound to the outer valve port extent coaxial to the valve stem. The two flow regimes have been identified by the simulation accounting for valve and piston motion and the transition between the regimes can be related to the location of the minimal effective cross-sectional area in the exhaust port system. For small valve lifts, the highest total pressure losses are generated with the compression and expansion process between valve head and valve seat [15]. However, for large valve lifts, a rather laminar flow field establishes in this region and the highest total pressure losses are induced in the junction region. Hence, the characteristics of the total pressure losses evolve different according to the valve lift regime and the total pressure losses are lower for large valve lifts than for small valve lifts. The present study demonstrates the physical mechanism for the transition of the discharge coefficient between the two flow regimes reported by Annand and Row [13].

The actual minimal effective cross-sectional area is difficult to be calculated, since this area does not only depend on the geometry, moreover on the present flow situation due to e.g. possible flow separation. Therefore, a formulation of the reference area approximating the minimal effective cross-sectional area is suggested, where the valve curtain area is used in the regime before the minimal effective cross-sectional area in the exhaust port is reached. This leads to a formulation, where the coefficient can be used to relate the valve to the efficiency of the exhaust port geometry.

The exhaust port geometry utilized for the present investigation is specific to a particular engine and therefore, the flow features demonstrated are thought to occur in real internal combustion engines. Nevertheless, reciprocating internal combustion engines have commonly two exhaust ports and the exhaust gasses are collected downstream in a manifold. Additionally, the occurrence of the two exhaust port flow regimes is not related to the present geometry, but to the existence of a translation of the smallest effective cross-sectional area from a cross-sectional area dependent on the valve lift to a cross-sectional area independent of the valve lift. This is the case for the most automotive internal combustion engines. The geometrical shape of the exhaust port and the valves determines at which valve lift to valve head diameter ratio $L_{v} / D_{v}$ the transition between the two exhaust port flow regimes occurs. The prolonged exhaust pipe and the flat piston shape are fictitious. Therefore, the flow structures developing in this exhaust pipe are not expected to evolve in the same manner in an engine. However, the flow structures generated by the valve port are characteristic for the individual exhaust port design. It has been shown that the valve motion has an effect on the mass flow rate distribution between the two exhaust ports and additionally, the flow structures generated appear different. These two global characteristics, mass flow rate alterations and flow structure changes, are expected to occur generally with two exhaust ports, where the valve port orifices are located at different distances to the junction outlet. For the present investigated geometry, the junction of the valve ports is located not far from the combustion chamber. The effect of dissimilar mass flow rate distributions through the individual valve port might be reduced when the junction of the valve ports is translated to a further downstream location and enhanced when the junction of the valve ports is shifted further upstream. 


\section{Acknowledgments}

This work was supported by the Competence Center for Gas Exchange (CCGEx) and the Swedish Energy Agency (STEM). The computational resources provided through the Swedish National Infrastructure for Computing (SNIC 2013/1-72) are greatly acknowledged.

\section{References}

[1] H. Perez-Blanco, Experimental characterization of mass, work and heat flows in an air cooled, single cylinder engine, Energy Conversion and Management 45 (2) (2004) 157 - 169.

[2] J. Caton, J. Heywood, An experimental and analytical study of heat transfer in an engine exhaust port, International Journal of Heat and Mass Transfer 24 (4) (1981) 581-595.

[3] A. Torregrosa, V. Bermúdez, P. Olmeda, O. Fygueroa, Experimental assessment for instantaneous temperature and heat flux measurements under diesel motored engine conditions, Energy Conversion and Management 54 (1) (2012) $57-66$.

[4] K. Atashkari, N. Nariman-Zadeh, M. Gölcü, A. Khalkhali, A. Jamali, Modelling and multi-objective optimization of a variable valve-timing spark-ignition engine using polynomial neural networks and evolutionary algorithms, Energy Conversion and Management 48 (3) (2007) 1029 - 1041.

[5] B. Jayashankara, V. Ganesan, Effect of fuel injection timing and intake pressure on the performance of a DI diesel engine - a parametric study using CFD, Energy Conversion and Management 51 (10) (2010) 1835 - 1848

[6] G. Fontana, E. Galloni, Variable valve timing for fuel economy improvement in a small spark-ignition engine, Applied Energy 86 (1) (2009) 96-105.

[7] G. Blair, F. Drouin, Relationship between discharge coefficients and accuracy of engine simulation, Tech. rep., SAE Technical Paper (1996).

[8] G. P. Blair, D. McBurney, P. McDonald, P. McKernan, R. Fleck, Some fundamental aspects of the discharge coefficients of cylinder porting and ducting restrictions, Training 2008 (1998) 1113.

[9] S. Bohac, K. Landfahrer, Effects of pulsating flow on exhaust port flow coefficients, SAE Int. J. Engines (1999-01-0214).

[10] A. Algieri, An experimental analysis of the fluid dynamic efficiency of a production spark-ignition engine during the intake and exhaust phase, ISRN Mechanical Engineering 2011.

[11] J. W. Harrington, Visualization of the flow of exhaust through an internal combustion engine exhaust port, $\mathrm{Ph} . \mathrm{D}$. thesis, Massachusetts Institute of Technology, Department of Mechanical Engineering (1979).

[12] K. Tanaka, Air flow through exhaust valve of conical seat., in: Proceedings of Third International Congress for Applied Mechanics, Vol. 1, 1931, pp. 287-295.

[13] W. J. D. Annand, G. E. Roe, Gas flow in the internal combustion engine : power, performance, emission control, and silencing, G. T. Foulis, 1974.

[14] M. Jia, M. Xie, T. Wang, Z. Peng, The effect of injection timing and intake valve close timing on performance and emissions of diesel pcci engine with a full engine cycle cfd simulation, Applied Energy 88 (9) (2011) 2967-2975.

[15] Y. Wang, B. Semlitsch, M. Mihaescu, L. Fuchs, Flow induced energy losses in the exhaust port of an internal combustion engine, Journal of Fluids Engineering 137 (1) (2014) 011105.
[16] B. Semlitsch, Y. Wang, M. Mihăescu, Flow effects due to pulsation in an internal combustion engine exhaust port, Energy Conversion and Management 86 (2014) 520-536.

[17] H. Aghaali, H.-E. Ångström, Turbocharged si-engine simulation with cold and hot-measured turbocharger performance maps, in: ASME Turbo Expo 2012: Turbine Technical Conference and Exposition, American Society of Mechanical Engineers, 2012, pp. 671-679.

[18] H. Aghaali, H.-E. Angstrom, Demonstration of air-fuel ratio role in one-stage turbocompound diesel engines, Tech. rep., SAE Technical Paper (2013).

[19] B. Leonard, The ultimate conservative difference scheme applied to unsteady one-dimensional advection, Computer methods in applied mechanics and engineering 88 (1) (1991) 17-74.

[20] M. Darwish, F. Moukalled, Normalized variable and space formulation methodology for high-resolution schemes, Numerical Heat Transfer 26 (1) (1994) 79-96.

[21] C. Fureby, F. F. Grinstein, Large eddy simulation of highreynolds-number free and wall-bounded flows, Journal of Computational Physics 181 (1) (2002) 68-97.

[22] C. Hirt, A. A. Amsden, J. Cook, An arbitrary lagrangianeulerian computing method for all flow speeds, Journal of Computational Physics 14 (3) (1974) 227-253.

[23] J. Donea, A. Huerta, J.-P. Ponthot, A. Rodríguez-Ferran, Arbitrary lagrangian-eulerian methods, Encyclopedia of computational mechanics.

[24] Y. Wang, Numerical studies of flow and associated losses in the exhaust port of a diesel engine, Ph.D. thesis, KTH - Department of Mechanics (2013).

[25] B. Semlitsch, V. JyothishKumar, M. Mihaescu, L. Fuchs, E. Gutmark, M. Gancedo, Numerical flow analysis of a centrifugal compressor with ported and without ported shroud, SAE Technical Paper 2014-01-1655. 